\title{
*Manuscript
}

Click here to view linked References

1

\section{Pyrolysis of furniture wood waste: Decomposition and gases evolved.}

\section{Department of Chemical Engineering, University of Alicante, P.O. Box 99, E-03080 Alicante}

* Corresponding author. Tel. + 34965903400 - ext. 3003; Fax Nr. + 34965903826.

E-mail address: anaisabel.moreno@ua.es (Ana Isabel Moreno)

\section{Highlights:}

- Pyrolysis of furniture wood waste.

- Kinetic parameters of pyrolysis from TG analysis.

- Analysis of gas, volatile and semi-volatile products evolved.

\section{Abstract}

The pyrolysis of furniture wood waste was studied due to its importance as a thermochemical conversion process, and also because it is a step in the combustion process. Furniture wood contains organic additives and inorganic elements (being noteworthy the high content of Ti). These additives cause changes in the thermal processes.

A thermogravimetric analysis of the pyrolysis of furniture wood waste was carried out in a TGA apparatus using dynamic and dynamic + isothermal runs. The pyrolysis was modeled with acceptable approximation by three independent reactions, according to the decomposition of the main components of the wood (hemicellulose, cellulose and lignin).

The gaseous products evolved during the pyrolysis were measured by the TG-MS and TG-FTIR techniques. The maximum formation of gases occurs around $360{ }^{\circ} \mathrm{C}$. The $\mathrm{CO}_{2}$ formation remains until the end of the run, due to the wide range of lignin degradation.

In addition, runs to identify the volatile and semi-volatile compounds were also carried out in a laboratory scale tubular reactor at 500 and $850{ }^{\circ} \mathrm{C}$ and the results were compared with the pyrolysis of a cleaner wood.

\section{Keywords:}

Wood waste; Thermogravimetric analysis (TGA); TG-FTIR; TG-MS; Gases evolved. 


\section{Introduction}

Wood is being widely used as a renewable energy and it has several advantages over other biomass, for instance, higher energy content per volume, lower amount of ash, and a very low amount of nitrogen and sulfur. Nowadays, the main thermochemical technologies are pyrolysis, gasification and combustion [1].

This paper studies the pyrolysis conversion technology. Pyrolysis is thermal decomposition in the complete absence of air or oxygen. Biomass pyrolysis is often employed in chemical synthesis or energy production [2-5]. On the other hand, pyrolysis can be a step in the combustion process and some of the pollutants emitted in the combustion process are formed during the pyrolysis step. In a TG analysis, it is possible to distinguish the different stages of the material decomposition. Wood is a complex material which essentially contains hemicelluloses, cellulose, and lignin, so any decomposition kinetic model developed must consider the degradation of these three compounds. Many authors have studied the decomposition of these components, and they concluded that the decomposition of hemicelluloses and cellulose occurs quickly, in the approximate temperature range of $200{ }^{\circ} \mathrm{C}-380{ }^{\circ} \mathrm{C}$ and $250{ }^{\circ} \mathrm{C}-400{ }^{\circ} \mathrm{C}$, respectively. Lignin however, is harder to decompose and decomposes in a wide temperature range from $180{ }^{\circ} \mathrm{C}$ up to $900{ }^{\circ} \mathrm{C}$ and the generated solid residue is considerable [6-9].

Waste from furniture wood can also be considered for energy recovery, but with the inconvenience of the formation of pollutants due to the oils, adhesives, paints and varnishes used in the fabrication of the furniture [10]. This additional chemical content changes its behavior during thermal processes. For instance, some authors have studied the catalytic effect of some inorganic salts in doped wood and it was found that the temperature of degradation decreases [11-13]. On the other hand, other authors studied the thermal degradation of wood treated with urea formaldehyde (UF), melamine formaldehyde (MF) and phenol formaldehyde (PF) resins and the results were that the treated wood showed higher temperatures of degradation [14]. The gases evolved in thermal degradations have been studied using thermogravimetry/mass spectrometry (TG/MS) [15-20] and thermogravimetry/Fourier 
transformed infrared (TG/FTIR) [7,21-27]. These methods offer the advantage of being simultaneous and real-time measurements of the mixture of the generated products are done.

The gases evolved were also studied with the treated wood with melamine and urea additives and in thermal decomposition can produce some nitrogen compounds, such as ammonia, isocyanic acid, hydrogen cyanide and nitric oxides [28-29].In this work, it is assumed that the furniture wood has been treated with these adhesives and other products and the presence of some inorganic compounds can also be higher than in untreated wood. Therefore, a thermogravimetic analysis of furniture wood waste can provide information on the global effect of all additives present in the furniture wood.

Therefore, the objective of this work has been to obtain a kinetic model and the characterization of the products evolved during the pyrolysis of furniture wood waste. Furthermore, a characterization of a clean wood waste (solid wood) has also carried out, in order to compare the results obtained with the furniture wood waste.

\section{Materials and methods}

\subsection{Characteristics of the materials}

The furniture waste was collected from a Municipal Solid Waste Treatment Plant, after being crushed to a size less than $10 \mathrm{~cm}$. Prior to experiments, a sample around $10 \mathrm{~kg}$ was taken from different parts of the pile with the crushed material and another sample around of $10 \mathrm{~kg}$ of solid wood was collected from a furniture factory. Representative samples of both kinds of wood were dried in an oven at $105^{\circ} \mathrm{C}$ and grounded to a size less than $0.2 \mathrm{~mm}$.

The proximate analysis of the material consists of moisture, ash, volatile matter and fixed carbon determination. The moisture and ash content were determined using the European Standards CEN-TS 14774-1:2009 and 14775:2009, respectively [30-31]. The volatile matter (VM) was determined using the method developed by García et al. [32], that shows satisfactory results according to the standard methods, mainly on moisture and volatile matter values. The fixed carbon (FC) content was calculated by difference using the following balance:

$\% \mathrm{FC}=100-(\% \mathrm{Ash}+\% \mathrm{VM})$ 
An elemental analysis of the major elements $(\mathrm{C}, \mathrm{H}, \mathrm{N})$ was carried out in a Leco Micro TruSpec Elemental Analyzer [33]. Determination of the content of sulfur and chlorine was carried according to the European Standard CEN-TS 15289:2011 [34].

The Net Calorific Value (NCV) was determined using an AC-350 calorimetric bomb from Leco Instruments.

The content of hemicelluloses, cellulose and lignin were analyzed according to Rowel et al. [35] and test methods T12, T222 and T203 of the "Technical Association for the Pulp and Paper Industries" [36-38].

Table 1 shows the characteristics of the furniture wood waste and the solid wood.

\section{Table 1.}

As can be seen in Table 1, the more significant differences between both samples are the ash content and the nitrogen content. The difference in nitrogen content can be due to the presence of additives in the furniture wood, such as melamine and nitrogenated adhesives.

The major and minor elements were also determined. A multi-step pressurised digestion was carried out following the CEN-TS 15290:2011 Standard [39] for the determination of the major elements (Al, Ca, Mg, P, K, Si, Na and Ti) and following the CEN-TS 15297:2011 Standard for the minor elements (As, Cd, Co, Cr, $\mathrm{Cu}, \mathrm{Hg}, \mathrm{Mn}, \mathrm{Mo}, \mathrm{Ni}, \mathrm{Pb}, \mathrm{Sb}, \mathrm{V}$ and $\mathrm{Zn}$ ) [40]. Subsequently, the detection of the major elements was carried out by Inductively Coupled Plasma Optical Emission Spectrometry (ICP-OES) following the CEN-ISO 11885:2007 Standard [41]. The detection of the minor elements was carried out by Inductively Coupled Plasma Mass Spectrometry (ICP-MS) following the Standard CEN-ISO 17294-2:2003 [42]. Table 2 shows the major and minor elements of the furniture wood waste, which can be compared with other data of literature [43].

Table 2.

From Table 2, it can be observed that the concentrations of inorganic compounds in the furniture wood waste are higher than those of solid wood. Nevertheless, most of the elements 
detected are within the range of those indicated in literature.In addition, $\mathrm{Co}, \mathrm{Mo}$ and $\mathrm{Sb}$ can also be present in tree and waste woods. For instance, Reimann et al. [44] showed that the concentrations of these elements in birch and spruce wood were around $8-34 \mathrm{mg} / \mathrm{kg}$ d.b. for These concentration values of the wood furniture wastes are in the same order. Co, $2.1-3.3 \mathrm{mg} / \mathrm{kg}$ d.b. for Mo, $2.6-3.1 \mathrm{mg} / \mathrm{kg}$ d.b. for Sb. On the other hand, Saqib et al. [45] also detected concentration values around $1.5 \mathrm{mg} / \mathrm{kg}$ d.b. for Co and $0.6 \mathrm{mg} / \mathrm{kg}$ d.b. for $\mathrm{Sb}$.

The content of $\mathrm{Ti}$ in the furniture wood waste is much higher than those of the other woods. Therefore, this indicates that the sample does not correspond to clean and untreated wood.

FTIR analyses were also carried out to qualitatively determinate if there are some chemical substances in furniture wood waste. FTIR spectra were recorded in the wavelength range from 4000-600 $\mathrm{cm}^{-1}$ with a BRUKER IFS 66/S spectrometer with a DLaTGS detector. Resolution in FTIR was set at $4 \mathrm{~cm}^{-1}$ and spectra were collected at 64 scans. The FTIR analyses were performed with samples of furniture wood waste, solid waste and laminate sheets from the same furniture waste, in order to compare the spectra obtained (Figure 1). In addition, the nitrogen content of the laminate sheets was also determined as being $4.9 \mathrm{wt}$. \%. It is assumed that the laminate sheets used for this analysis are made of melamine resin and also show adhesive to fix the laminate sheets to the particle boards.

Figure 1 shows the FTIR spectra whose baselines were corrected and vector normalized.

\section{Figure 1.}

The spectrum of the laminate sheets shows more similarity to the furniture wood waste spectrum than to the solid wood spectrum. These similarities are mainly observed in the 1700$1300 \mathrm{~cm}^{-1}$ region. The differences between the solid wood spectrum and the spectra of the furniture waste and the laminate sheets can be due to the presence of additives in those treated, such as urea- formaldehyde (UF), melamine-urea-formaldehyde (MUF) and phenolformaldehyde (PF) resins [46-47]. Zhang et al. [46] show the FTIR spectra of the UF and MUF 
resins and they indicated that the peak at around $1650 \mathrm{~cm}^{-1}$ is due to $\mathrm{C}=\mathrm{O}$ stretching of primary

134

135

136

137

138

139

140

141 amides. This peak is also observed in the spectra of the furniture waste and the laminate sheets. The PF resin spectrum shows a peak at $1609 \mathrm{~cm}^{-1}$ [47], which is also observed in the spectra of the furniture waste and the laminate sheets.

\subsection{Thermogravimetric analysis}

A thermogravimetric analysis was carried out in a TGA apparatus (Perkin Elmer, model TG

STA6000) using dynamic and dynamic + isothermal runs. The sample temperature was measured with a sensor directly attached to the sample holder. The atmosphere used was nitrogen with a flow rate of $100 \mathrm{~mL} \mathrm{~min}^{-1}$.

Dynamic runs were carried out at different weights $(2.5,5$ and $10 \mathrm{mg})$ and different heating rates $\left(5,10\right.$ and $\left.20^{\circ} \mathrm{C} \mathrm{min}^{-1}\right)$, from the initial temperature up to $900{ }^{\circ} \mathrm{C}$.

Dynamic + isothermal runs were carried out with a constant heating rate until the required temperature was reached (between $280^{\circ} \mathrm{C}$ and $320^{\circ} \mathrm{C}$ ) and this final temperature was kept constant for a long period of time.

In addition, a dynamic run was also carried out with the solid wood at $10^{\circ} \mathrm{C} \mathrm{min}^{-1}$, to compare the thermal behavior between treated and untreated wood.

Furthermore, an experiment of Avicel PH-105 microcrystalline cellulose at a heating rate of 5 ${ }^{\circ} \mathrm{C} \min ^{-1}$ was done to verify the performance of the equipment. The kinetic values obtained agreed well with the results presented by Grønli et al. [48] in their round-robin study of pyrolysis kinetics of cellulose by thermogravimetry.

\subsection{TG-MS analysis}

The pyrolysis of furniture wood waste was also studied with a thermogravimetric analysis (TGA) coupled to a mass spectrometer (MS). A Mettler Toledo TGA/SDTA851e/LF/1600 (TGDTA) in series with a Pfeiffer Vacuum Quadrupole Mass Spectrometer (QMS) Thermostar GSD301T using an electron ionization voltage at $70 \mathrm{eV}$ was used. The mass of sample used in runs was around $3 \mathrm{mg}$. The pyrolysis analysis were performed at a heating rate of $30{ }^{\circ} \mathrm{C} \mathrm{min}^{-1} \mathrm{up}$ 
to a final temperature of $900^{\circ} \mathrm{C}$ with a flow rate of $100 \mathrm{~mL} / \mathrm{min}$ of helium (measured at room

160 temperature). The detection of the $4,13-18,25-32,35-46$ ions was carried out in one run and the $4,32,43-46,50-52,55-58,60,65,68,73,78,91,96,105,106$ ions in another run. The response of the different ions was divided by that of helium $(m / z=4)$ and subtracted from that corresponding to the beginning of the run.

\subsection{TG-FTIR analysis}

The TGA analysis was performed by TG STA6000 (Perkin Elmer) at a heating rate of $30^{\circ} \mathrm{C}$ $\mathrm{min}^{-1}$ from room temperature to $900{ }^{\circ} \mathrm{C}$, with a gas flow of $100 \mathrm{~mL} \mathrm{~min}{ }^{-1}$ of nitrogen. The mass of sample used was around $6 \mathrm{mg}$. The FTIR measurements were performed by a Nicolet 6700 spectrometer coupled to the TGA to measure the gas products from the wood decomposition. The transfer line and gas cell were heated at $230^{\circ} \mathrm{C}$, to prevent condensation of the gases produced. Resolution in FTIR was set at $4 \mathrm{~cm}^{-1}$ and spectra were collected at 32 scans in the range $400-4000 \mathrm{~cm}^{-1}$.

\subsection{Pollutant analysis}

Runs for the identification of volatile and semi-volatile compounds from pyrolysis were carried out in a laboratory scale horizontal quartz reactor at 500 and $850^{\circ} \mathrm{C}$. In this reactor, the sample was introduced inside a crucible and a small engine introduced it inside the reactor. This equipment has previously been described in detail by Font et al. [49]. Runs were carried out with $300 \mathrm{~mL} \mathrm{~min}^{-1}$ of nitrogen and with a feeding velocity of $1 \mathrm{~mm} \mathrm{~s}^{-1}$. The sample mass in all the runs was almost $100 \mathrm{mg}$.

Gases and volatile compounds were collected in Tedlar ${ }^{\circledR}$ bags and analyzed in three gas chromatographs; one with a thermal conductivity detector (TCD) to determine mainly $\mathrm{CO}$ and $\mathrm{CO}_{2}$, another with a flame ionization detector (FID) to determine hydrocarbons and the third apparatus was a GC-MS with a DB-624 capillary column (30 m x $0.25 \mathrm{~mm} \times 1.4 \mu \mathrm{m})$ to determine volatile compounds. Due to the $\mathrm{N}$ content in the furniture wood waste, it is expected that its pyrolysis produces nitrogen oxides, $\mathrm{NH}_{3}, \mathrm{HCN}$ and another volatile and semi-volatile nitrogen compounds. Nitrogen oxides $\left(\mathrm{NO}\right.$ and $\left.\mathrm{NO}_{2}\right)$ were analyzed with a gas analyzer IM- 
186

187

188

189

190

191

192

193

194

195

196

197

198

199

200

201

202

203

204

205

206

207

208

209

210

2800 (Environmental Equipment Germany GmbH). Ammonia produced was collected by absorption in a $0.1 \mathrm{wt} . \%$ citric acid solution and analyzed by ion chromatography and hydrogen cyanide and other volatile nitrogen compounds were detected with a GC-MS with DB-624 capillary column. Semi-volatile compounds were collected in an adsorbent XAD-2 resin, extracted with solvent in accordance with the EPA Method 3545 [50] and analyzed with GCMS by the isotope dilution method for the polycyclic aromatic hydrocarbons (PAHs). The identification of semi-volatile compounds was done comparing unknown mass spectra with NIST database reference spectra. A semiquantitative estimation of the yields was calculated with the response factors of the deuterated internal standards with the nearest retention time, according to the EPA 8270D method.

Furthermore, major elements $(\mathrm{C}, \mathrm{H}, \mathrm{N}, \mathrm{S})$ contained in each of the chars obtained were measured in a Leco Micro TruSpec Elemental Analyzer.

\section{Results and discussion}

3.1. Kinetic study

Prior to carrying out the runs for determination of the kinetics, it was verified that a variation at sample weight between 2.5 - $10 \mathrm{mg}$ has no influence on the TG results. Therefore, the following TG runs were carried out with $5 \mathrm{mg}$ of sample.

Figure 2 shows the experimental TG plots for furniture wood waste pyrolysis at heating rates of 5, 10, $20^{\circ} \mathrm{C} \mathrm{min}^{-1}$. In this Figure, the weight fraction represents the weight fraction of the solid, sum of the residue formed and the non-reacted initial solid. The weight fraction is on dry basis (sample weight at $150{ }^{\circ} \mathrm{C}$ was taken as initial weight). The value of increment of temperature, corresponding to the DTA, for a run is also plotted in a convenient scale, from $-10{ }^{\circ} \mathrm{C}$, which represents a strong endothermic process, to $10^{\circ} \mathrm{C}$, corresponding to a strong exothermic process.

Figure 2. 
The decomposition of carbonates occurs between $600-750{ }^{\circ} \mathrm{C}$ [51]. Figure 2 shows a slight

212 weight loss in this range of temperatures. The amount of carbonates can change significantly between samples, therefore data from more than $600{ }^{\circ} \mathrm{C}$ were omitted to carry out the kinetic correlation.

215 Figure 3 shows the DTG curve for a pyrolysis run, in order to obtain more information about the

216 fractions that can be considered in wood waste decomposition. Considering the main

217 components of the wood (hemicelluloses, cellulose, and lignin) and their decomposition

218 temperatures [6-9] $\left(200-380^{\circ} \mathrm{C}\right.$ for the hemicelluloses, $250-400{ }^{\circ} \mathrm{C}$ for the cellulose, and 180

$219{ }^{\circ} \mathrm{C}$ up to $900{ }^{\circ} \mathrm{C}$ for the lignin) the wide band could be the sum of three peaks, the first two of

220 them very close and the third one is a wide peak.

Figure 3.

222

223

224

225

From Figure 4, the differences in the thermal degradation can be seen between treated and untreated wood. According to Deka et al. [14], the treatment of wood with urea formaldehyde (UF), melamine formaldehyde (MF) and phenol formaldehyde (PF) increases the major degradation temperature. However, in this study, the temperature at the maximum degradation rate was $356{ }^{\circ} \mathrm{C}$ for the furniture wood waste, and $366^{\circ} \mathrm{C}$ for the solid wood. This decrease in the pyrolysis temperature is probably due to the inorganic salt content [11-13]. Another contrast between both types of wood is the final residue, which is due to the different ash content, $1.8 \%$ for the furniture wood waste and $0.3 \%$ for the solid wood.

Figure 4.

The dynamic and dynamic + isothermal runs were carried out to correlate a pyrolysis kinetic model. The results of the two dynamic + isothermal experiments carried out in pyrolytic conditions are shown in Appendix A.

\subsection{Pyrolysis model}

The pyrolysis kinetic model was proposed considering the main components of the wood (hemicelluloses, cellulose, and lignin): 
$w_{S_{10}}$ Solid $_{1} \stackrel{1}{\rightarrow}\left(w_{S_{10}}-v_{1 \infty}\right)$ Char $_{1}+v_{1 \infty}$ Volatiles $_{1}$

$w_{S_{20}}$ Solid $_{2} \stackrel{2}{\rightarrow}\left(w_{S_{20}}-v_{2 \infty}\right)$ Char $_{2}+v_{2 \infty}$ Volatiles $_{2}$

$w_{S_{30}}$ Solid $_{3} \stackrel{3}{\rightarrow}\left(w_{S_{30}}-v_{3 \infty}\right)$ Char $_{3}+v_{3 \infty}$ Volatiles $_{3}$

240 where Solid $_{1}$ is hemicellulose, Solid 2 is cellulose, Solid 3 is lignin, "Volatiles ${ }_{i}$ " are the gases and

241 condensable volatiles evolved in the corresponding reactions $(i=1-3)$, and "Char ${ }_{i}$ " is the char

242 formed in the decomposition of each Solid . On the other hand, the small letters represent the

243 yield coefficients representative of each reaction. Moreover, each fraction has a yield coefficient

244 that represents the maximum mass fractions obtainable by each reaction. In this way, $v_{i \infty}$ is the

245 yield coefficient for the Volatiles $_{i}$.

246 The conversion degree for each reaction is defined as the ratio between the weight fraction of

247 solid reacted at any time $\left(w_{S_{i 0}}-w_{S_{i}}\right)$ and the corresponding initial fraction of this component

$248 w_{S_{i 0}}$, or the ratio between the weight fraction of volatiles obtained at any time $\left(V_{i}\right)$ and the

249 corresponding yield coefficient or the mass fraction of volatiles at infinite time, taking into

250 account that direct relation between formation the volatiles and reacted solids is assumed for

251 each fraction [52].

252

$\alpha_{i}=\frac{w_{S_{i 0}}-w_{S_{i}}}{w_{S_{i 0}}}=\frac{V_{i}}{v_{i \infty}}, \quad i=1-3$

$253 w_{S_{i 0}}$ is the weight fraction of each Solid $_{i}$ that is in the original material, and consequently

$254 \quad \sum_{i=1}^{3} w_{S_{i 0}}=1$

255 Considering the mass balance between products and reactants and the conversion degrees, the

256 kinetic equations for the pyrolysis runs can be defined as follows:

$257 \quad \frac{d\left(V_{i} / V_{i \infty}\right)}{d t}=\frac{d \alpha_{i}}{d t}=k_{i}\left(1-\alpha_{i}\right)^{n_{i}}=k_{i}\left(1-\frac{V_{i}}{v_{i \infty}}\right)^{n_{i}}$

258 with the kinetic constants following the Arrhenius equation:

$259 \quad k_{i}=k_{i 0} \exp \left(-\frac{E_{i}}{R T}\right), \quad i=1-3$ 
By integration of these equations, $\alpha_{i}$ can be calculated at each time with the temperature

261

262

263 program; the relationship between the $\alpha_{i}$ values and the weight fraction measured in the thermobalance $(w)$ is related with the volatiles obtained $(\mathrm{V})$ by

$w=1-V=1-\left(v_{1 \infty} \alpha_{1}+v_{2 \infty} \alpha_{2}+v_{3 \infty} \alpha_{3}\right)$

\subsection{Pyrolysis: kinetic parameters}

The dynamic and the dynamic + isothermal runs for pyrolysis were correlated with the same set of parameters.

The calculated values were obtained by integration of the differential equations presented in the kinetic model by the Euler method considering and testing that the intervals of time were small enough to make the integration errors negligible. The optimization method of the function with Solver in a spreadsheet in Excel was used to minimize the differences between the experimental and calculated weight loss and their derivatives.

The objective function (OF) to minimize was the sum of the square differences between the experimental and calculated weight fractions and their derivatives multiplied by a factor:

$\mathrm{OF}=\sum_{\mathrm{m}=1}^{\mathrm{M}} \sum_{\mathrm{j}=1}^{\mathrm{N}}\left(\mathrm{w}_{\mathrm{m}, \mathrm{j}}^{\mathrm{exp}}-\mathrm{w}_{\mathrm{m}, \mathrm{j}}^{\mathrm{cal}}\right)^{2}+$ factor $\sum_{\mathrm{m}=1}^{\mathrm{M}} \sum_{\mathrm{j}=1}^{\mathrm{N}}\left(\frac{\mathrm{dw}_{\mathrm{m}, \mathrm{j}}^{\mathrm{exp}}}{\mathrm{dt}}-\frac{\mathrm{dw}_{\mathrm{m}, \mathrm{j}}^{\mathrm{cal}}}{\mathrm{dt}}\right)^{2}$

where $\mathrm{M}$ is the number of runs and $\mathrm{N}$ is the number of points in each run.

In order to decrease the great interrelation existing among the pre-exponential factor, the apparent activation energy and the reaction order, the optimization is carried out in terms of a "comparable kinetic constant" $\mathrm{k}_{\mathrm{i}}^{*}$ instead of optimization of $\mathrm{k}_{0 \mathrm{i}}[53]$.

$K_{i}^{*}=k_{i}(0.64)^{n_{i}}=k_{0 i} \exp \left(-\frac{E_{i}}{R T_{\max }}\right)(0.64)^{n_{i}}$

Table 3 shows the set of parameters optimized and Figure 5 shows the calculated evolution of volatiles corresponding to each fraction for a $10^{\circ} \mathrm{C} / \mathrm{min}$ run.

The first fraction decomposes at $250-450^{\circ} \mathrm{C}$, with apparent activation energy around 139 $\mathrm{kJ} / \mathrm{mol}$, and probably corresponds mainly to hemicelluloses, as this value is close to the range of 
values (110-132 kJ/mol) proposed for hemicelluloses in literature [54-56]. The maximum yield of volatiles corresponding to hemicellulose $(0.238)$ is close to the hemicellulose content $(0.180)$ indicating that this fraction is volatilized, whereas for the other fractions, cellulose and lignin, the volatiles evolved are less than their content indicating the formation of a carbonaceous residue mainly from these fractions.

Table 3.

A second fraction decomposes at $280-380^{\circ} \mathrm{C}$ with apparent activation energy around 176 $\mathrm{kJ} / \mathrm{mol}$. Other studies have found that cellulose decomposes in the range $300-400{ }^{\circ} \mathrm{C}$ with an apparent activation energy around $150-250 \mathrm{~kJ} / \mathrm{mol}[48,55-57]$.

The last fraction corresponds mainly to lignin and decomposes in a wide range of temperature from $200{ }^{\circ} \mathrm{C}$ until the end of the decomposition, with an apparent activation energy around 116 $\mathrm{kJ} / \mathrm{mol}$, a value less than those of hemicelluloses and cellulose. Grønly et al. [57] also indicated that the decomposition of lignin separated from cellulose and hemicellulose takes place in a wide range of temperature and the value of activation proposed was $46 \mathrm{~kJ} / \mathrm{mol}$.

In spite of the previous comments, it must be emphasized that the kinetic parameters are those obtained from the best correlation of the data, so the first fraction corresponding to the hemicellulose can include other portions of cellulose and/or lignin, and that acceptable correlations can also be obtained with other values of activation energy and reaction orders of lignin, taking into account the great interrelation between the kinetic parameters.

Figures 3 and A.1 show the calculated values that are very close to the calculated ones according to the model presented. Small differences between experimental and calculated values were obtained with the other two runs.

\section{Figure 5.}

\subsection{TG-MS analysis}

Figure 6 shows the intensities of some ions in the TG-MS run, corresponding to $\mathrm{H}_{2} \mathrm{O}(\mathrm{m} / \mathrm{z} 18)$, $\mathrm{CO}_{2}(\mathrm{~m} / \mathrm{z} 44), \mathrm{CO}(\mathrm{m} / \mathrm{z} 28)$ and $\mathrm{CH}_{4}\left(\mathrm{~m} / \mathrm{z} 15\right.$ corresponding to $\left.\mathrm{CH}_{3}{ }^{+}\right)$. At the beginning, there is a 
small formation of water, due to the humidity of the sample. The formation of $\mathrm{CO}_{2}, \mathrm{CO}$ and

311

312 $\mathrm{CH}_{4}$ starts at approximately $200{ }^{\circ} \mathrm{C}$ that means that the decomposition of the organic matter has begun. These curves have a maximum peak at $348^{\circ} \mathrm{C}$. At $650{ }^{\circ} \mathrm{C}$, there is another peak in the $\mathrm{CO}_{2}$ curve that is due to the decomposition of the carbonates that the wood waste contains.

In addition, small peaks corresponding to some light hydrocarbons, aldehydes and alcohols have been observed in a temperature range of $200-600{ }^{\circ} \mathrm{C}$. On the other hand, compounds as $\mathrm{HCl}$, benzene, toluene and xylenes are below the limit of detection.

\section{Figure 6.}

\subsection{TG-FTIR analysis}

Figure 7 shows the spectra of gas generated at the maximum temperature of decomposition (365 $\left.{ }^{\circ} \mathrm{C}\right)$. Nearly all peaks have been identified. The main peak corresponds to $\mathrm{CO}_{2}$ with a wavelength between $2300-2400 \mathrm{~cm}^{-1}$.

Figure 8 shows the evolution of the formation of $\mathrm{CO}_{2}$ during the thermal degradation. The shape of $\mathrm{CO}_{2}$ curve fitted well with the degradation of the main components, as shown in Figure 8 . $\mathrm{CO}_{2}$ formation remains until the end of the experiment, due to the wide range of lignin degradation. In addition, a small peak at $650-750{ }^{\circ} \mathrm{C}$ is observed due to the degradation of carbonates.

Peaks from 2200 to $2300 \mathrm{~cm}^{-1}$ correspond to CO. The evolution of the formation of $\mathrm{CO}$ is plotted in Figure 9. Note that the maximum peak of $\mathrm{CO}$ formed occurs before that of the maximum peak of $\mathrm{CO}_{2}$, and moreover the continuous formation of $\mathrm{CO}$ until the end is negligible, in contrast to the $\mathrm{CO}_{2}$ formation. The maximum formation of $\mathrm{CO}$ occurs at $325^{\circ} \mathrm{C}$, as shown in Figure 9.

Peaks ranging from 3400 to $4000 \mathrm{~cm}^{-1}$ of wavelengths are characteristic of water, as shown in Figure 7. The wood waste sample was previously dried, so the water formed is due to the thermal degradation of the wood waste; the formation of water occurs when the loss weight is maximal (temperature range: $200-380^{\circ} \mathrm{C}$ ). 
The wavelength range $2700-3100 \mathrm{~cm}^{-1}$ corresponds to compounds with a C-H bond

337 (hydrocarbon group), shown in Figure 7.

On the other hand, $\mathrm{C}=\mathrm{O}$ bond shows its wavelength at $1660-1820 \mathrm{~cm}^{-1}$. The characteristic compounds are ketones, aldehydes, esters and acids; the curve of formation is very similar to the C-H bond curve.

Figure 7.

Figure 8 .

Figure 9.

\subsection{Volatile and semi-volatile compounds.}

Two experiments of pyrolysis for each wood sample, at 500 and $850{ }^{\circ} \mathrm{C}$, were carried out in a laboratory scale tubular reactor. The residence time of the gas inside the central part of the reactor is around 4-6s. Runs for the analysis of volatiles were triplicated. The mean values of the yield of the volatile gases generated are shown in Appendix B (Table B.1.). Table 4 shows the main volatile gases generated in the pyrolysis.

\section{Table 4.}

Oxygenated compound yields are due to the oxygen present in the wood in pyrolysis processes.

Note the high yield of $\mathrm{CO}$ and the yield increase of $\mathrm{H}_{2}$ at $850{ }^{\circ} \mathrm{C}$ with respect to pyrolysis at 500 ${ }^{\circ} \mathrm{C}$, that is probably as a consequence of the gasification of the carbonaceous residue and volatile gases formed with the water formed in the pyrolysis (Equation 12).

$\langle\mathrm{C}\rangle+\mathrm{H}_{2} \mathrm{O} \rightarrow \mathrm{CO}+\mathrm{H}_{2}$

On the other hand, it can be observed in the TG-FTIR analysis that the maximum CO formation occurs at $325^{\circ} \mathrm{C}$ (Figure 9). This difference between the TG-FTIR analysis and the experiments in the laboratory scale tubular reactor is due to the difference in the heating rate. In the pyrolysis run in the tubular reactor at $850^{\circ} \mathrm{C}$, the heating rate was around $300{ }^{\circ} \mathrm{C} \mathrm{min}^{-1}$; whereas in the TG-FTIR, the heating rate was $30^{\circ} \mathrm{C} \mathrm{min}^{-1}$. This fast heating rate produces secondary reactions 
at high temperatures, which cause the water formed to react with the carbonaceous residue and other volatile gases generated in the primary reactions. Instead, due to the slow heating rate, these secondary reactions do not occur in the TG analysis. When the first reaction products are formed, the temperature in the furnace chamber of the TGA apparatus is not as high as in the tubular reactor, therefore these products do not continue to react and leave the furnace chamber.

366 The differences between the TG analysis and the experiments in the laboratory scale tubular

367 reactor can also be observed in the final carbonaceous residue, being $25 \%$ and $20 \%$ (at $850{ }^{\circ} \mathrm{C}$ ),

368 respectively.

369 In the volatile gases evolved, the differences between the furniture wood waste and the solid 370 wood are, obviously, in the nitrogen compounds.

371 In the pyrolysis of furniture wood waste, $\mathrm{NH}_{3}$ was found in a high proportion at $850{ }^{\circ} \mathrm{C}$ and the 372 yield was lower at $500^{\circ} \mathrm{C}$. Meanwhile, in the pyrolysis of solid wood, $\mathrm{NH}_{3}$ was negligible. The nitrogen content in the furniture wood waste can be due to the nitrogenated organic resins, such

374 as MF, MUF and UF resins, and the chemical structure of these compounds promotes the 375 formation of ammonia [28-29,58].

Other nitrogen compounds appear in the furniture wood waste pyrolysis at $850{ }^{\circ} \mathrm{C}$, such as acetonitrile, 2-propenenitrile, pyrrole and pyridine, 2-methyl (Table B.1.). NO was detected in high proportion in pyrolysis at $850^{\circ} \mathrm{C}$ and the yields were similar for the pyrolysis of both samples. However, $\mathrm{NO}_{2}$ was not detected in any of the runs. $\mathrm{HCN}$ was found in all pyrolysis runs, but their yields were very small (Table 4).

$381 \mathrm{NH}_{3}$ shows a higher yield than $\mathrm{HCN}$, which is in accordance with other studies [58-59].

The main volatile organic compounds in all the runs are: methane, ethene, propene, benzene and toluene. Table 5 shows the concentration of the 16 polyaromatic hydrocarbons recognized by USEPA as priority PAHs. The highest yield of PAHs is found in pyrolysis of furniture wood waste at 850 


\section{Table 5.}

Furthermore, 198 semi-volatile compounds were identified and quantified, results are shown in Appendix C. Comparing the pyrolysis runs, it can be observed that the amount of semi-volatiles evolved during the pyrolysis of furniture wood waste is higher than during the pyrolysis of solid wood, but within the same magnitude order.

Table 6 lists the percentage contribution by groups of compounds of the yield of the semivolatiles obtained in pyrolysis. It can be observed that the aromatics obtained at $850{ }^{\circ} \mathrm{C}$ are higher than at $500^{\circ} \mathrm{C}$. On the other hand, the oxygenated compounds predominate in pyrolysis at $500{ }^{\circ} \mathrm{C}$. Regarding the differences due to the different material pyrolyzed, a contribution of nitrogen can be observed compounds in the pyrolysis of the furniture wood waste. On the other hand, the yield of nitrogen compounds is negligible in the pyrolysis of solid wood.

\section{Table 6.}

Char and gases were collected from the laboratory scale pyrolysis; however the liquid fraction was complicated to collect, due to the laboratory dimensions of the experiments.

The chars obtained in the experimental pyrolysis were analyzed with an Elemental Analyzer to determinate the C, H, N, S content; the results are shown in Table 7. The chars obtained could be used as fuel, due to their high carbon content. Furthermore, the nitrogen content has decreased compared with the initial wood waste and the sulfur content is also very low, therefore the emissions of $\mathrm{NO}_{\mathrm{x}}$ and $\mathrm{SO}_{\mathrm{x}}$ would be low.

\section{Table 7.}

Mass balances of $\mathrm{C}$ taking into account the total carbon in $\mathrm{CO}_{\mathrm{x}}$, total volatiles, total semivolatiles and total $\mathrm{C}$ in the char are shown in Appendix D. 
412 A chemical characterization of furniture wood waste and solid wood (treated and untreated wood) has been carried out to observe the possible differences. The FTIR analyses show some

414 differences between the furniture wood waste and the solid wood. The elemental analyses also

415 show an important difference in the nitrogen content, which can be due to the content of some

416 resins. On the other hand, the ICP analyses show the higher concentration of some elements in

417 furniture wood waste in comparison with solid wood. Particularly noteworthy is the high

418 concentration of $\mathrm{Ti}$ in the furniture wood waste sample.

419 This work has studied the global effect of all additives present in furniture wood waste.

420 Regarding the TG analyses, these reveal that the temperature at the maximum degradation rate

421 is lower for furniture wood waste compared to solid wood. Regarding the gases evolved, in the

422 pyrolysis of furniture wood waste, $\mathrm{NH}_{3}$ was found in a high proportion, whereas meanwhile, in

423 the pyrolysis of solid wood, $\mathrm{NH}_{3}$ was negligible. The nitrogen content in the furniture wood

424 waste can be due to nitrogenated organic resins, and the chemical structure of these compounds

425 promotes the formation of ammonia. Other nitrogen compounds were also found in the

426 pyrolysis gases evolved.

427 On the other hand, a kinetic model for the furniture wood waste was proposed and tested to

428 satisfactorily correlate the experimental results, considering the three components of wood:

429 hemicellulose, cellulose and lignin.

\section{Acknowledgment:}

431 Support for this work was provided by the Spanish Ministerio de Economía y Competividad,

432 Research Project RETO CTQ2013-41006-R (Spain), and PROMETEOII/2014/007 and

433 Gerónimo Forteza FPA/2014/081 from Generalitat Valenciana (Spain).

\section{References:}


[1] A.V. Bridgwater, Renewable fuels and chemicals by thermal processing of biomass, Chemical Engineering Journal, 91, (2003) 87.

[2] A.V. Bridgwater and G.V.C. Peacocke, Fast pyrolysis processes for biomass, Renewable and Sustainable Energy Reviews, 4, (2000) 1.

[3] A. Demirbaş, Gaseous products from biomass by pyrolysis and gasification: effects of catalyst on hydrogen yield, Energy Conversion and Management, 43, (2002) 897.

[4] S. Yaman, Pyrolysis of biomass to produce fuels and chemical feedstocks, Energy Conversion and Management, 45, (2004) 651.

[5] M. Nasir Uddin, W.M.A.W. Daud and H.F. Abbas, Potential hydrogen and noncondensable gases production from biomass pyrolysis: Insights into the process variables, Renewable and Sustainable Energy Reviews, 27, (2013) 204.

[6] L. Gašparovič, Z. Koreňová and L. Jelemenský, Kinetic study of wood chips decomposition by TGA, Chemical Papers, 64, (2010) 174.

[7] Q. Liu, Z. Zhong, S. Wang and Z. Luo, Interactions of biomass components during pyrolysis: A TG-FTIR study, Journal of Analytical and Applied Pyrolysis, 90, (2011) 213.

[8] S. Wang, X. Guo, K. Wang and Z. Luo, Influence of the interaction of components on the pyrolysis behavior of biomass, Journal of Analytical and Applied Pyrolysis, 91, (2011) 183

[9] H. Yang, R. Yan, H. Chen, D.H. Lee and C. Zheng, Characteristics of hemicellulose, cellulose and lignin pyrolysis, Fuel, 86, (2007) 1781.

[10] A. Khalfi, G. Trouvé, R. Delobel and L. Delfosse, Correlation of CO and PAH emissions during laboratory-scale incineration of wood waste furnitures, Journal of Analytical and Applied Pyrolysis, 56, (2000) 243. 
[11] M. Müller-Hagedorn, H. Bockhorn, L. Krebs and U. Müller, A comparative kinetic study on the pyrolysis of three different wood species, Journal of Analytical and Applied Pyrolysis, 68-69, (2003) 231.

[12] I.-Y. Eom, J.-Y. Kim, T.-S. Kim, S.-M. Lee, D. Choi, I.-G. Choi and J.-W. Choi, Effect of essential inorganic metals on primary thermal degradation of lignocellulosic biomass, Bioresource Technology, 104, (2012) 687.

[13] A. Khelfa, A. Bensakhria and J.V. Weber, Investigations into the pyrolytic behaviour of birch wood and its main components: Primary degradation mechanisms, additivity and metallic salt effects, Journal of Analytical and Applied Pyrolysis, 101, (2013) 111.

[14] M. Deka, C.N. Saikia and K.K. Baruah, Studies on thermal degradation and termite resistant properties of chemically modified wood, Bioresource Technology, 84, (2002) 151.

[15] P. Szabó, G. Várhegyi, F. Till and O. Faix, Thermogravimetric/mass spectrometric characterization of two energy crops, Arundo donax and Miscanthus sinensis, Journal of Analytical and Applied Pyrolysis, 36, (1996) 179.

[16] C.J. Gómez, E. Mészáros, E. Jakab, E. Velo and L. Puigjaner, Thermogravimetry/mass spectrometry study of woody residues and an herbaceous biomass crop using PCA techniques, Journal of Analytical and Applied Pyrolysis, 80, (2007) 416.

[17] N. Worasuwannarak, T. Sonobe and W. Tanthapanichakoon, Pyrolysis behaviors of rice straw, rice husk, and corncob by TG-MS technique, Journal of Analytical and Applied Pyrolysis, 78, (2007) 265.

[18] A.G. Barneto, J.A. Carmona, J.E.M. Alfonso and J.A.C. Ferrer, Use of thermogravimetry/mass spectrometry analysis to explain the origin of volatiles produced during biomass pyrolysis, Industrial and Engineering Chemistry Research, 48, (2009) 7430. 
[19] A. Albis, E. Ortiz, A. Suárez and I. Piñeres, TG/MS study of the thermal devolatization of Copoazú peels (Theobroma grandiflorum), Journal of Thermal Analysis and Calorimetry, 115, (2014) 275.

[20] D. López-González, M. Fernandez-Lopez, J.L. Valverde and L. Sanchez-Silva, Thermogravimetric-mass spectrometric analysis on combustion of lignocellulosic biomass, Bioresource Technology, 143, (2013) 562.

[21] Q. Liu, S. Wang, Y. Zheng, Z. Luo and K. Cen, Mechanism study of wood lignin pyrolysis by using TG-FTIR analysis, Journal of Analytical and Applied Pyrolysis, 82, (2008) 170 .

[22] E. Biagini, F. Barontini and L. Tognotti, Devolatilization of Biomass Fuels and Biomass Components Studied by TG/FTIR Technique, Industrial \& Engineering Chemistry Research, 45, (2006) 4486.

[23] N. Gao, A. Li, C. Quan, L. Du and Y. Duan, TG-FTIR and Py-GC/MS analysis on pyrolysis and combustion of pine sawdust, Journal of Analytical and Applied Pyrolysis, $100,(2013) 26$.

[24] E. Granada, P. Eguía, J.A. Vilan, J.A. Comesaña and R. Comesaña, FTIR quantitative analysis technique for gases. Application in a biomass thermochemical process, Renewable Energy, 41, (2012) 416.

[25] W. de Jong, A. Pirone and M.A. Wójtowicz, Pyrolysis of Miscanthus Giganteus and

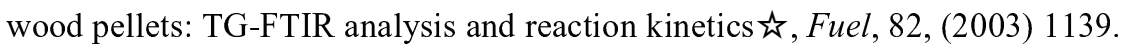

[26] X. Gu, X. Ma, L. Li, C. Liu, K. Cheng and Z. Li, Pyrolysis of poplar wood sawdust by TG-FTIR and Py-GC/MS, Journal of Analytical and Applied Pyrolysis, 102, (2013) 16.

[27] J. Giuntoli, S. Arvelakis, H. Spliethoff, W. de Jong and A.H.M. Verkooijen, Quantitative and Kinetic Thermogravimetric Fourier Transform Infrared (TG-FTIR) Study of Pyrolysis of Agricultural Residues: Influence of Different Pretreatments, Energy \& Fuels, 23, (2009) 5695. 
[28] P. Girods, A. Dufour, Y. Rogaume, C. Rogaume and A. Zoulalian, Pyrolysis of wood waste containing urea-formaldehyde and melamine-formaldehyde resins, Journal of Analytical and Applied Pyrolysis, 81, (2008) 113.

[29] P. Girods, A. Dufour, Y. Rogaume, C. Rogaume and A. Zoulalian, Thermal removal of nitrogen species from wood waste containing urea formaldehyde and melamine formaldehyde resins, Journal of Hazardous Materials, 159, (2008) 210.

[30] European Committee for Standardization (CEN),. Technical Specification: Solid biofuels. Determination of moisture content. Oven dry method. Part 1: Total moisture. Reference method. CEN-TS 14774-1:2009.

[31] European Committee for Standardization (CEN), Technical Specification: Solid biofuels. Determination of ash content. CEN-TS 14775:2009.

[32] R. García, C. Pizarro, A.G. Lavín and J.L. Bueno, Biomass proximate analysis using thermogravimetry, Bioresource Technology, 139, (2013) 1.

[33] European Committee for Standardization (CEN), Technical Specification: Solid biofuels. Determination of total content of carbon, hydrogen and nitrogen. Instrumental methods. CEN-TS 15104:2011.

[34] European Committee for Standardization (CEN), Technical Specification: Solid biofuels. Determination of total content of sulfur and chlorine. CEN-TS 15289:2011.

[35] R.M. Rowell, Rowell, J. K., Young, R. A., Paper and Composites from Agro-Based Resources., CRC Press, 1996, p.

[36] Technical Association for the Pulp and Paper Industries (TAPPI), Preparation of extractive free-wood. TAPPI Test Method T12 os-75. TAPPI Press, Atlanta, US., 1978.

[37] Technical Association for the Pulp and Paper Industries (TAPPI), Acid-insoluble in wood and pulp. TAPPI Test Method T222 os-74. TAPPI Press, Atlanta, US, 1978.. 
[38] Technical Association for the Pulp and Paper Industries (TAPPI), Alpha-, Beta- and Gamma Cellulose in pulp. TAPPI Test Method T203 os-74. TAPPI Press, Atlanta, US , 1978.

[39] European Committee for Standardization (CEN), Technical Specification: Solid biofuels.

Determination of major elements. Al, Ca, Mg, P, K, Si, Na and Ti. CEN-TS 15290:2011.

[40] European Committee for Standardization (CEN), Technical Specification: Solid biofuels. Determination of minor elements. As, $\mathrm{Cd}, \mathrm{Co}, \mathrm{Cr}, \mathrm{Cu}, \mathrm{Hg}, \mathrm{Mn}, \mathrm{Mo}, \mathrm{Ni}, \mathrm{Pb}, \mathrm{Sb}, \mathrm{V}$ and $\mathrm{Zn}$. CEN-TS 15297:2011.

[41] European Committee for Standardization (CEN), Technical Specification: Water quality. Determination of selected by inductively coupled plasma optical emission spectrometry (ICP-OES). CEN-ISO 11885:2007.

[42] European Committee for Standardization (CEN), Technical Specification: Water quality. Application of inductively coupled plasma mass spectrometry (ICP-MS). Part 2: Determination of 62 elements. CEN-ISO 17294-2:2003.

[43] European Committee for Standardization (CEN), Technical Specification: Solid biofuels. Fuel specifications and clases. Part 1: General requirements. CEN-TS 14961- 1:2010.

[44] C. Reimann, R.T. Ottesen, M. Andersson, A. Arnoldussen, F. Koller and P. Englmaier, Element levels in birch and spruce wood ashes - green energy?, Science of The Total Environment, 393, (2008) 191.

[45] N. Saqib and M. Bäckström, Trace element partitioning in ashes from boilers firing pure wood or mixtures of solid waste with respect to fuel composition, chlorine content and temperature, Waste Management.

[46] J. Zhang, X. Wang, S. Zhang, Q. Gao and J. Li, Effects of Melamine Addition Stage on the Performance and Curing Behavior of Melamine-Urea-Formaldehyde (MUF) Resin, 2013, p. 
L.W. Liying Guo, Jixin Li, in 2nd International Conference on Electronic \& Mechanical Engineering and Information Technology, Atlantis Press, Paris, France,

Shenyang, Liaoning, China, 2012.

M. Grønli, M.J. Antal and G. Várhegyi, A Round-Robin Study of Cellulose Pyrolysis Kinetics by Thermogravimetry, Industrial \& Engineering Chemistry Research, 38, (1999) 2238.

[49] R. Font, I. Aracil, A. Fullana, I. Martín-Gullón and J.A. Conesa, Semivolatile compounds in pyrolysis of polyethylene, Journal of Analytical and Applied Pyrolysis, 68-69, (2003) 599.

[50] U.S. Environmental Protection Agengcy (USEPA), Pressurized Fluid Extraction (PFE). Method 3545. Washington, D.C., 1996.

[51] L. Han, Q. Wang, Q. Ma, C. Yu, Z. Luo and K. Cen, Influence of $\mathrm{CaO}$ additives on wheat-straw pyrolysis as determined by TG-FTIR analysis, Journal of Analytical and Applied Pyrolysis, 88, (2010) 199.

R. Font, I. Martín-Gullón, M. Esperanza and A. Fullana, Kinetic law for solids decomposition. Application to thermal degradation of heterogeneous materials, Journal of Analytical and Applied Pyrolysis, 58-59, (2001) 703.

[53] I. Martín-Gullón, M.F. Gómez-Rico, A. Fullana and R. Font, Interrelation between the kinetic constant and the reaction order in pyrolysis, Journal of Analytical and Applied Pyrolysis, 68-69, (2003) 645.

[54] R. Font, A. Marcilla, E. Verdú and J. Devesa, Thermogravimetric kinetic study of the pyrolysis of almond shells and almond shells impregnated with CoCl2, Journal of Analytical and Applied Pyrolysis, 21, (1991) 249.

R. Font, J.A. Conesa, J. Moltó and M. Muñoz, Kinetics of pyrolysis and combustion of pine needles and cones, Journal of Analytical and Applied Pyrolysis, 85, (2009) 276. 
[56] R. Font, J. Moltó, A. Gálvez and M.D. Rey, Kinetic study of the pyrolysis and

Figure 4. Weight fraction and its derivate from pyrolysis of furniture wood waste and solid 604 wood.

605 
Figure 5. Evolution of the mass fraction of volatiles for each reaction in furniture wood waste 607 pyrolysis: 1 (hemi-cellulose), 2 (cellulose), 3 (lignin).

608 Figure 6. Intensities of some ions in a TG-MS run for wood waste pyrolysis. Ions: $15\left(\mathrm{CH}_{4}\right), 18$ $609\left(\mathrm{H}_{2} \mathrm{O}\right), 28(\mathrm{CO})$ and $44\left(\mathrm{CO}_{2}\right)$.

610 Figure 7. FTIR spectra of gas products from wood waste pyrolysis at $365^{\circ} \mathrm{C}$.

611 Figure 8. Evolution of formation of $\mathrm{CO}_{2}$ during wood waste pyrolysis.

612 Figure 9. Evolution of formation of $\mathrm{CO}$ during wood waste pyrolysis.

613 Table 4. Main volatile gases in wood waste pyrolysis

614 Table 5. Concentration of16 priority PAHs in wood waste pyrolysis.

615 Table 6. Total concentration of semi-volatiles and percent contributions of compounds to the 616 total yield of semi-volatiles.

617 Table 7. Analysis elemental of char from wood waste pyrolysis. 


\section{Tables:}

Table 1. Characterization of the furniture wood waste and the solid wood

\begin{tabular}{lcc}
\hline & $\begin{array}{c}\text { Furniture wood } \\
\text { waste }\end{array}$ & Solid wood \\
\hline Moisture (wt. \%) & $9-11$ & $10-14$ \\
\hline Analysis on dry basis & & \\
\hline Proximate analysis & $1.8 \pm 0.1$ & $0.3 \pm 0.1$ \\
Ash content (wt. \%) & $77.3 \pm 0.4$ & $80.1 \pm 0.2$ \\
Volatile matter (wt. \%) & $20.9 \pm 0.4$ & $19.6 \pm 0.2$ \\
Fixed carbon by difference (wt. \%) & & \\
\hline Elemental analysis & $47.9 \pm 0.03$ & $52.7 \pm 0.1$ \\
C (wt. \%) & $6.0 \pm 0.1$ & $6.2 \pm 0.1$ \\
H (wt. \%) & $2.9 \pm 0.6$ & nd \\
N (wt. \%) & $0.05 \pm 0.01$ & $0.007 \pm 0.005$ \\
S (wt. \%) & $41.4 \pm 0.6$ & $40.8 \pm 0.1$ \\
O estimated by difference (wt. \%) & $0.06 \pm 0.01$ & $0.02 \pm 0.01$ \\
Cl (wt. \%) & $15.8 \pm 0.1$ & $19.5 \pm 0.5$ \\
\hline Net calorific value (MJ kg-1) & & - \\
\hline Composition & $2.72 \pm 0.05$ & - \\
Ethanol extracts (wt. \%) & $18.0 \pm 3.6$ & - \\
Hemicellulose (wt. \%) & $44.7 \pm 2.5$ & \\
Cellulose (wt. \%) & $33.0 \pm 1.1$ & \\
Lignin (wt. \%) & & \\
\hline
\end{tabular}

* The standard deviations were calculated from 3 values.

nd: not detected $<0.01 \%$ 
Table 2. Major and minor elements of furniture wood waste. Comparison with other types of wood [43].

\begin{tabular}{|c|c|c|c|c|}
\hline & $\begin{array}{c}\text { Furniture } \\
\text { wood waste } \\
\text { (mg/kg d.b.) }\end{array}$ & $\begin{array}{l}\text { Solid wood } \\
\text { (mg/kg d.b.) }\end{array}$ & $\begin{array}{c}\text { Coniferous wood } \\
\text { (without bark) }^{\mathrm{a}} \\
(\mathrm{mg} / \mathrm{kg} \mathrm{d.b.})\end{array}$ & $\begin{array}{c}\text { Coniferous bark } \\
\text { wood }^{\mathrm{a}} \\
(\mathbf{m g} / \mathbf{k g ~ d . b .})\end{array}$ \\
\hline \multicolumn{5}{|c|}{ Major elements } \\
\hline Al & $480 \pm 10$ & $30 \pm 20$ & $30-400$ & $400-1200$ \\
\hline $\mathbf{C a}$ & $1590 \pm 240$ & $260 \pm 5$ & $500-1000$ & $1000-15000$ \\
\hline $\mathbf{F e}$ & $280 \pm 30$ & $25 \pm 4$ & $10-100$ & $100-800$ \\
\hline $\mathbf{K}$ & $340 \pm 150$ & $160 \pm 90$ & $200-500$ & $1000-3000$ \\
\hline Mg & $320 \pm 80$ & $100 \pm 30$ & $100-200$ & $400-1500$ \\
\hline $\mathbf{N a}$ & $300 \pm 120$ & $20 \pm 10$ & $10-50$ & $70-2000$ \\
\hline $\mathbf{P}$ & $100 \pm 20$ & $20 \pm 10$ & $50-100$ & $20-600$ \\
\hline Si & $2150 \pm 140$ & $109 \pm 3$ & $100-200$ & $500-5000$ \\
\hline $\mathbf{T i}$ & $1600 \pm 200$ & $2.1 \pm 0.8$ & $<20$ & n.i. \\
\hline \multicolumn{5}{|c|}{ Minor elements } \\
\hline As & $0.4 \pm 0.03$ & $0.01 \pm 0.004$ & $<0.1-1.0$ & $0.1-4.0$ \\
\hline Cd & $1.0 \pm 0.1$ & $0.1 \pm 0.02$ & $<0.05-0.50$ & $0.2-1.0$ \\
\hline Co & $1.1 \pm 0.1$ & $0.05 \pm 0.004$ & n.i. & n.i. \\
\hline $\mathrm{Cr}$ & $6.7 \pm 1.4$ & $2.0 \pm 1.3$ & $0.2-10$ & $1-10$ \\
\hline $\mathbf{C u}$ & $6.4 \pm 0.7$ & $1.4 \pm 1.4$ & $0.5-10$ & $3-30$ \\
\hline $\mathbf{H g}$ & $0.03 \pm 0.04$ & $0.01 \pm 0.003$ & $<0.02-0.05$ & $0.01-0.1$ \\
\hline Mn & $40.0 \pm 3.6$ & $46.8 \pm 7.1$ & $40-200$ & $9-480$ \\
\hline Mo & $0.3 \pm 0.03$ & $0.02 \pm 0.02$ & n.i. & n.i. \\
\hline $\mathbf{N i}$ & $1.2 \pm 0.3$ & $0.04 \pm 0.07$ & $<0.1-10$ & $2-20$ \\
\hline $\mathbf{P b}$ & $6.3 \pm 3.6$ & $0.04 \pm 0.06$ & $<0.5-10$ & $1-30$ \\
\hline $\mathbf{S b}$ & $2.0 \pm 0.4$ & $0.01 \pm 0.01$ & n.i. & n.i. \\
\hline $\mathbf{V}$ & $0.9 \pm 0.04$ & $0.1 \pm 0.002$ & $<2$ & $0.7-2.0$ \\
\hline $\mathrm{Zn}$ & $69.4 \pm 2.0$ & $7.7 \pm 0.9$ & $5-50$ & $70-200$ \\
\hline
\end{tabular}

${ }^{a}$ Variation of typical values. CEN-TS 14961-1:2010 [43]

n.i.: not indicated

* The standard deviations were calculated from 3 values.

Table 3: Kinetic parameters obtained for the pyrolysis of furniture wood waste.

\begin{tabular}{lcccc}
\hline Reaction & $\begin{array}{c}\text { Mass fraction } \\
\text { of volatiles, } \mathbf{V}_{\mathbf{i}}\end{array}$ & $\boldsymbol{k}\left(\mathbf{s}^{-\mathbf{1}}\right)$ & $\mathbf{E}(\mathbf{k J} / \mathbf{m o l})$ & $\mathbf{n}$ \\
\hline 1 & 0.238 & $1.735 \cdot 10^{10}$ & 139 & 3.0 \\
2 & 0.239 & $4.894 \cdot 10^{12}$ & 176 & 1.0 \\
3 & 0.211 & $9.204 \cdot 10^{8}$ & 116 & 5.6 \\
\hline Residue & $\mathbf{0 . 3 1 2}$ & & & \\
(mass fraction) & & & & \\
\hline
\end{tabular}


Table 4. Main volatile gases in wood waste pyrolysis.

\begin{tabular}{|c|c|c|c|c|}
\hline \multirow[b]{2}{*}{ Compound } & \multicolumn{2}{|c|}{ Pyrolysis at $500{ }^{\circ} \mathrm{C}$ (mg/kg sample) } & \multicolumn{2}{|c|}{ Pyrolysis at $850^{\circ} \mathrm{C}(\mathrm{mg} / \mathrm{kg}$ sample) } \\
\hline & $\begin{array}{c}\text { Furniture wood } \\
\text { waste }\end{array}$ & Solid wood & $\begin{array}{c}\text { Furniture wood } \\
\text { waste }\end{array}$ & Solid wood \\
\hline \multicolumn{5}{|l|}{ Main gases: } \\
\hline $\mathrm{H}_{2}$ & $160 \pm 20$ & $300 \pm 40$ & $7100 \pm 2700$ & $10700 \pm 1200$ \\
\hline $\mathrm{CO}_{2}$ & $63000 \pm 4600$ & $60000 \pm 4600$ & $164000 \pm 15000$ & $140000 \pm 5000$ \\
\hline $\mathrm{CO}$ & $30000 \pm 4100$ & $39000 \pm 2700$ & $371000 \pm 22000$ & $393000 \pm 27000$ \\
\hline NO & $3800 \pm 400$ & $3200 \pm 500$ & $7900 \pm 1000$ & $8400 \pm 400$ \\
\hline $\mathrm{NO}_{2}$ & $\mathrm{nd}^{\mathrm{a}}$ & $\mathrm{nd}^{\mathrm{a}}$ & $\mathrm{nd}^{\mathrm{a}}$ & $\mathrm{nd}^{\mathrm{a}}$ \\
\hline $\mathrm{CH}_{4}$ & $5400 \pm 190$ & $5900 \pm 800$ & $56800 \pm 400$ & $59600 \pm 2000$ \\
\hline Ethene & $1380 \pm 70$ & $1530 \pm 240$ & $34400 \pm 1100$ & $37000 \pm 1300$ \\
\hline Propene & $1360 \pm 100$ & $1541 \pm 210$ & $2860 \pm 600$ & $3440 \pm 220$ \\
\hline Benzene & $340 \pm 50$ & $280 \pm 40$ & $17500 \pm 2300$ & $20600 \pm 600$ \\
\hline Toluene & $460 \pm 260$ & nd & $5430 \pm 2670$ & $3680 \pm 800$ \\
\hline $\mathrm{NH}_{3}$ & $90 \pm 40$ & $5 \pm 4$ & $4000 \pm 2100$ & $8 \pm 9$ \\
\hline $\mathrm{HCN}$ & $30 \pm 10$ & $20 \pm 2$ & $90 \pm 40$ & $90 \pm 20$ \\
\hline
\end{tabular}

${ }^{\mathrm{a}} \mathrm{NO}_{2}$ not detected: $<100 \mathrm{mg} \mathrm{NO} / \mathrm{kg}$ sample.

Table 5. Concentration of 16 priority PAHs in wood waste pyrolysis.

\begin{tabular}{|l|c|c|c|c|}
\cline { 2 - 5 } \multicolumn{1}{c|}{} & \multicolumn{2}{c|}{$\begin{array}{c}\text { Pyrolysis 500 } \\
\text { (mg/kg } \mathbf{C}\end{array}$} & \multicolumn{2}{c|}{$\begin{array}{c}\text { Pyrolysis 850 } \\
\text { (mg/kg } \mathbf{~ C a m p l e ) ~}\end{array}$} \\
\cline { 2 - 5 } & $\begin{array}{c}\text { Furniture } \\
\text { wood waste }\end{array}$ & Solid wood & $\begin{array}{c}\text { Furniture } \\
\text { wood waste }\end{array}$ & Solid wood \\
\hline Naphthalene & 70 & 6 & 15700 & 5000 \\
\hline Acenaphthylene & 20 & 2 & 15900 & 2300 \\
\hline Acenaphthene & nd & nd & 460 & 80 \\
\hline Fluorene & nd & 2 & 3540 & 820 \\
\hline Phenanthrene & 7 & 1 & 1080 & 1080 \\
\hline Anthracene & 3 & 1 & 380 & 440 \\
\hline Fluoranthene & nd & nd & 260 & 330 \\
\hline Pyrene & 5 & nd & 350 & 340 \\
\hline Benzo[a]anthracene & nd & nd & 130 & 130 \\
\hline Chrysene & nd & nd & 80 & 90 \\
\hline Benzo[b]fluoranthene & nd & nd & nd & 60 \\
\hline Benzo[k]fluoranthene & nd & nd & 60 & 70 \\
\hline Benzo[a]pyrene & nd & nd & 50 & 100 \\
\hline Indeno[1,2,3-cd]pyrene & nd & nd & 10 & 40 \\
\hline Dibenzo[a,h]anthracene & nd & nd & 1 & 7 \\
\hline Benzo[g,h,i]perylene & nd & nd & 10 & 30 \\
\hline
\end{tabular}

nd: not detected $<1 \mathrm{mg} / \mathrm{kg}$ sample 
Table 6. Total concentration of semi-volatiles and percent contributions of compounds to the total yield of semi-volatiles.

\begin{tabular}{|c|c|c|c|c|}
\hline & \multirow{2}{*}{\multicolumn{2}{|c|}{ Pyrolysis $500{ }^{\circ} \mathrm{C}$}} & \multirow{2}{*}{\multicolumn{2}{|c|}{ Pyrolysis $850{ }^{\circ} \mathrm{C}$}} \\
\hline & & & & \\
\hline & $\begin{array}{c}\text { Furniture } \\
\text { wood waste }\end{array}$ & Solid wood & $\begin{array}{c}\text { Furniture } \\
\text { wood waste }\end{array}$ & Solid wood \\
\hline $\begin{array}{l}\text { Total semi-volatiles (included } \\
\text { PAHs) } \\
\text { Concentration (mg/kg sample) }\end{array}$ & 33570 & 22030 & 57380 & 31350 \\
\hline Percent contribution, $\%$ & & & & \\
\hline Aromatics & 26.6 & 32.6 & 82.6 & 79.7 \\
\hline Oxygenated compounds & 43.0 & 49.7 & 9.6 & 15.5 \\
\hline Other nitrogen compounds & 2.0 & 0.0 & 3.1 & 0.1 \\
\hline Hydrocarbons & 9.0 & 0.2 & 0.1 & 0.0 \\
\hline Cyclic hidrocarbons & 4.3 & 4.2 & 0.1 & 0.0 \\
\hline Heterocyclic compound & 13.8 & 13.2 & 4.5 & 4.6 \\
\hline Terpenes & 0.5 & 0.0 & 0.0 & 0.0 \\
\hline Other sulfur compounds & 0.8 & 0.0 & 0.0 & 0.0 \\
\hline
\end{tabular}

Table 7. Analysis elemental of char from wood waste pyrolysis.

\begin{tabular}{|c|c|c|c|c|c|}
\hline \multicolumn{2}{|c|}{ Char } & C (wt.\%) & H (wt.\%) & N (wt.\%) & S (wt.\%) \\
\hline $\begin{array}{c}\text { Pyrolysis } \\
\text { at 500 }\end{array}$ & $\begin{array}{c}\text { Furniture } \\
\text { wood waste }\end{array}$ & $68.9 \pm 0.6$ & $3.43 \pm 0.02$ & $1.52 \pm 0.04$ & nd \\
\cline { 2 - 6 } & Solid wood & $81.8 \pm 0.3$ & $3.37 \pm 0.12$ & nd & nd \\
\hline \multirow{2}{*}{$\begin{array}{c}\text { Pyrolysis } \\
\text { at 850 }\end{array}$} & $\begin{array}{c}\text { Furniture } \\
\text { wood waste }\end{array}$ & $78.6 \pm 1.0$ & $1.06 \pm 0.02$ & $1.02 \pm 0.09$ & nd \\
\cline { 2 - 6 } & Solid wood & $93.0 \pm 0.2$ & $0.99 \pm 0.01$ & nd & nd \\
\hline
\end{tabular}

$\mathrm{nd}<0.01 \%$

* The standard deviations were calculated from 3 values. 
Figures:

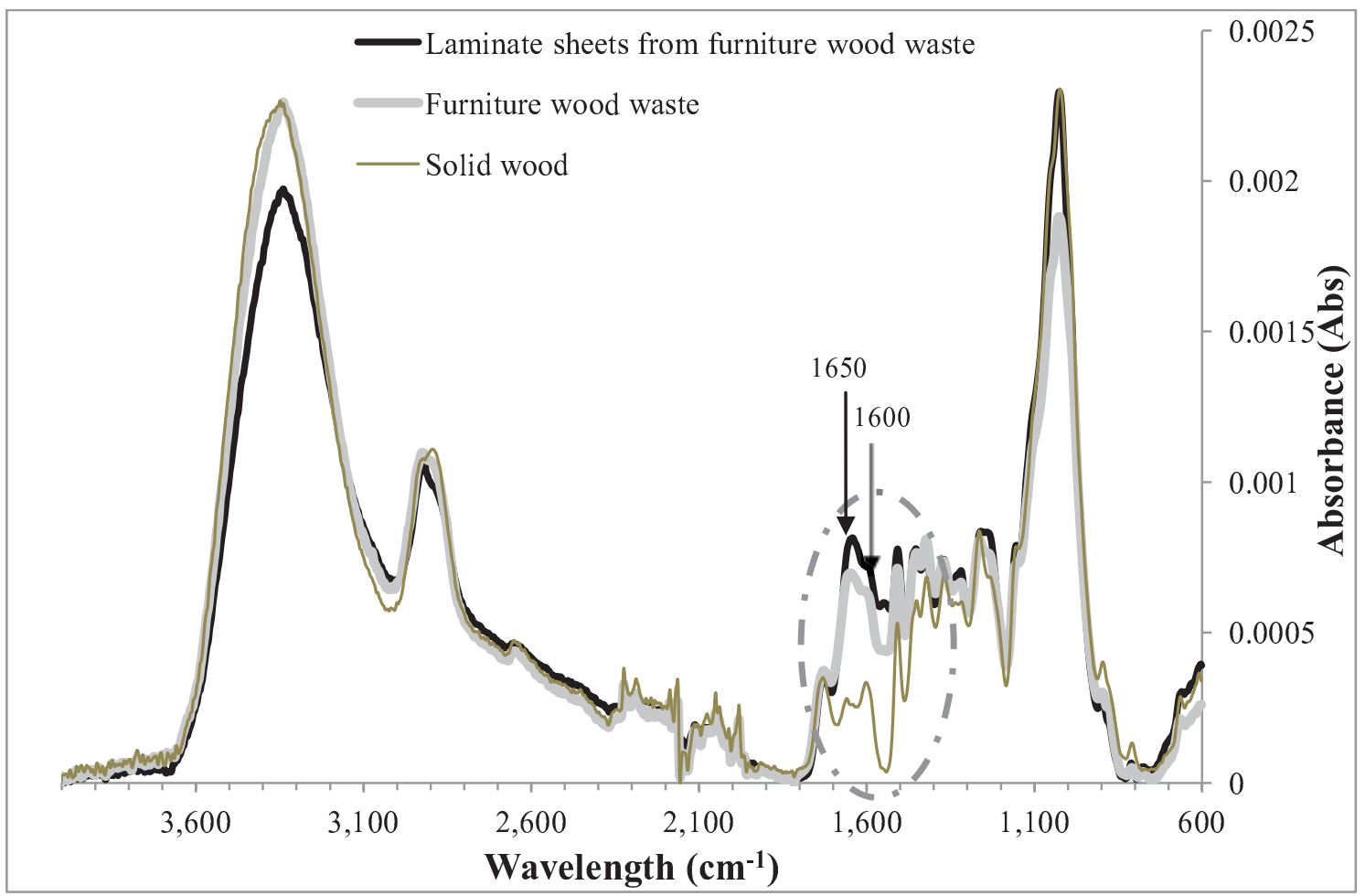

Figure 1. FTIR spectra of furniture wood waste, solid wood and laminate sheets from furniture wood waste.

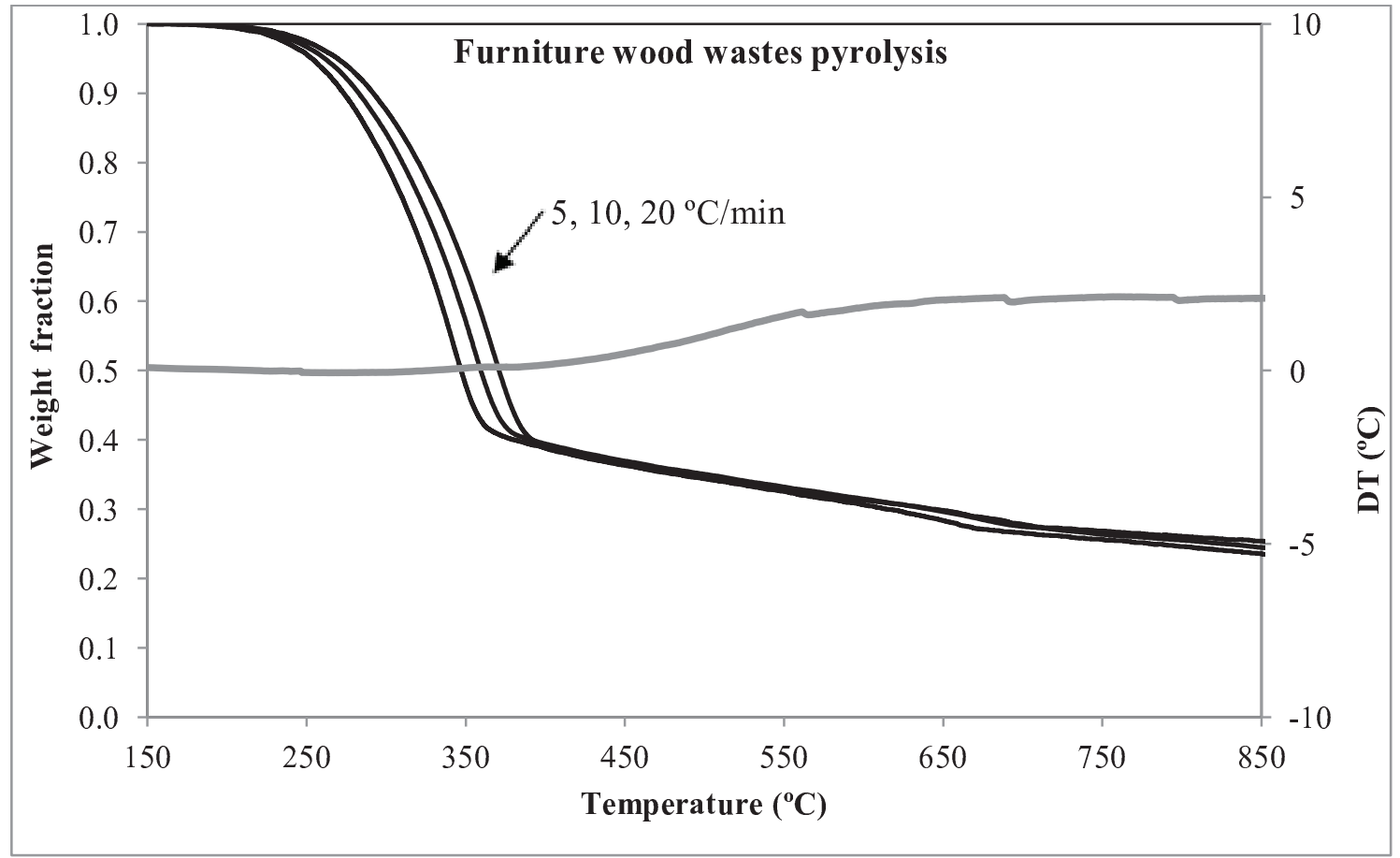

Figure 2. Furniture wood waste pyrolysis at several heating rates: $5,10,20^{\circ} \mathrm{C} \mathrm{min}{ }^{-1}$ (experimental curves). 


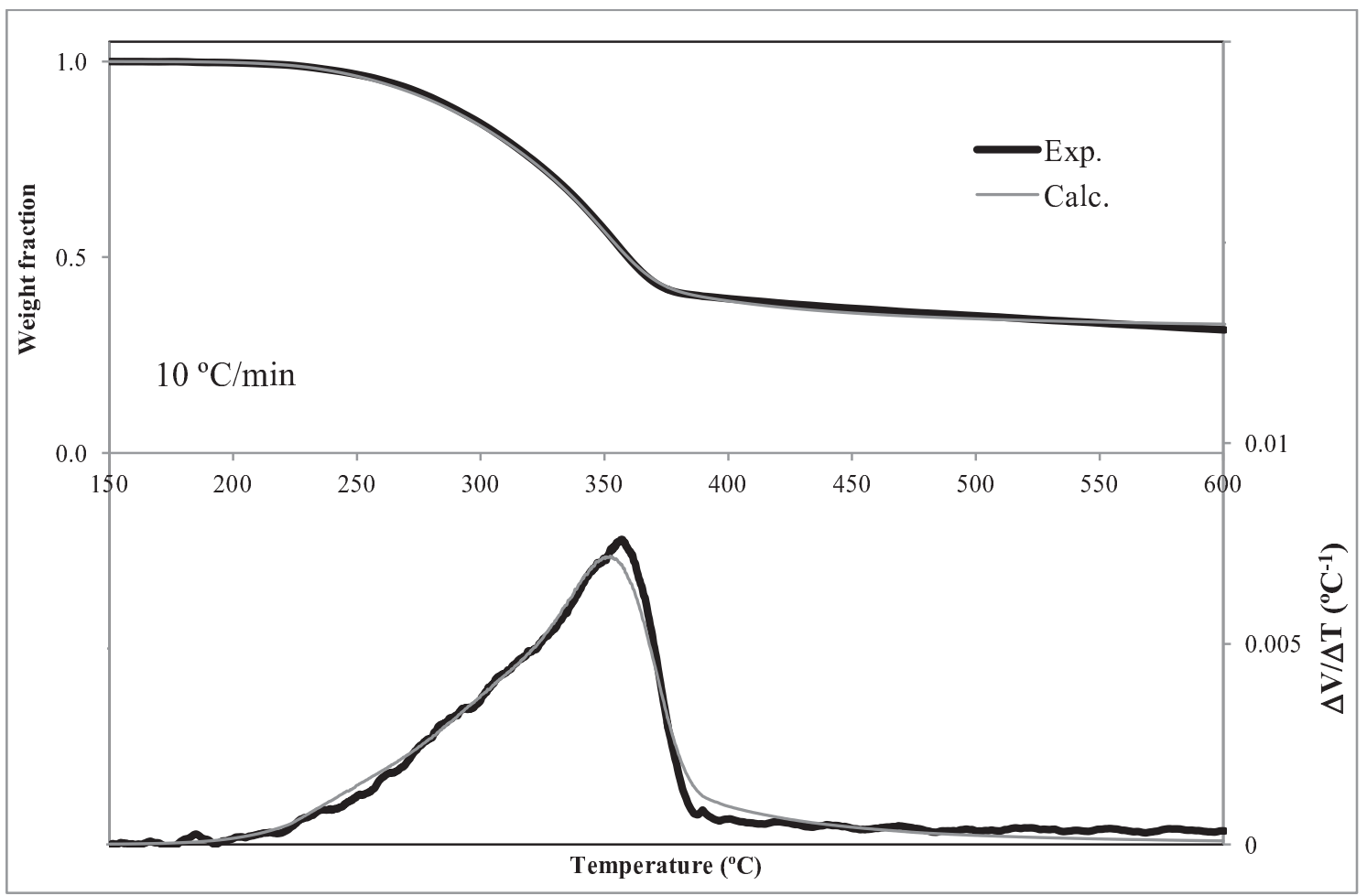

Figure 3. Weight fraction and its derivate from a pyrolysis run. Experimental and calculated curves.

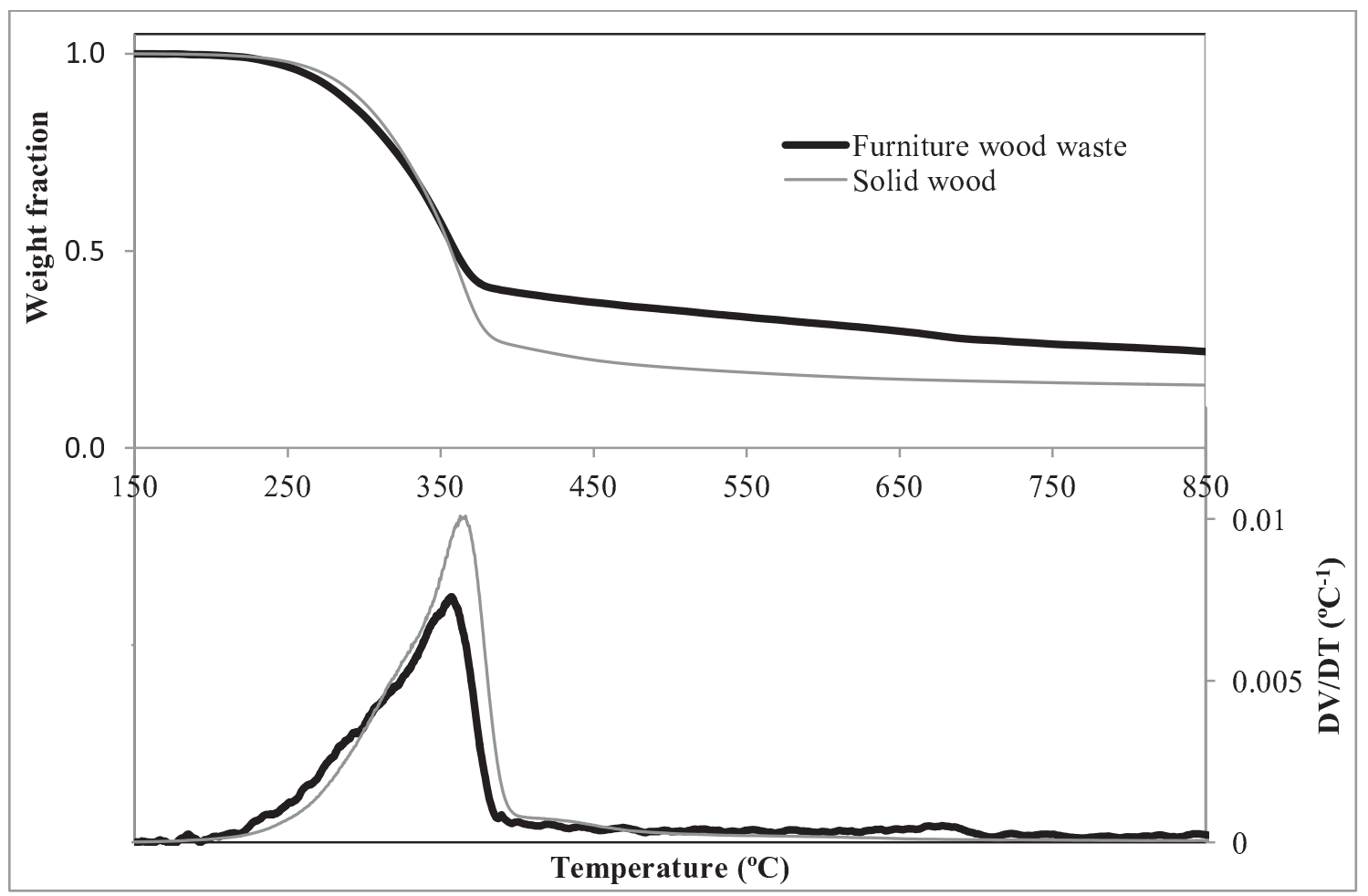

Figure 4. Weight fraction and its derivate from pyrolysis of furniture wood waste and solid wood. 


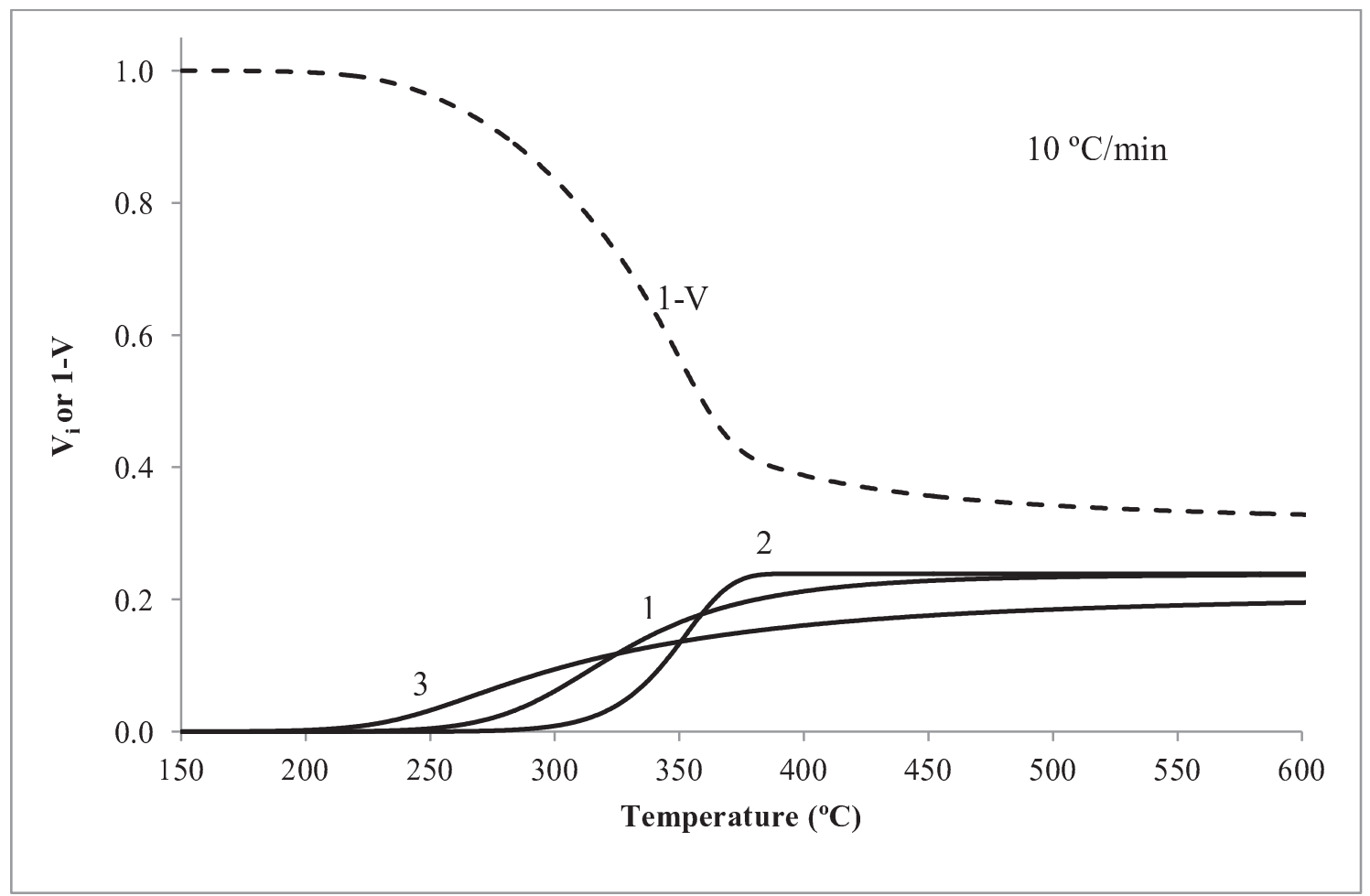

Figure 5. Evolution of the mass fraction of volatiles for each reaction in furniture wood waste pyrolysis: 1 (hemi-cellulose), 2 (cellulose), 3 (lignin)

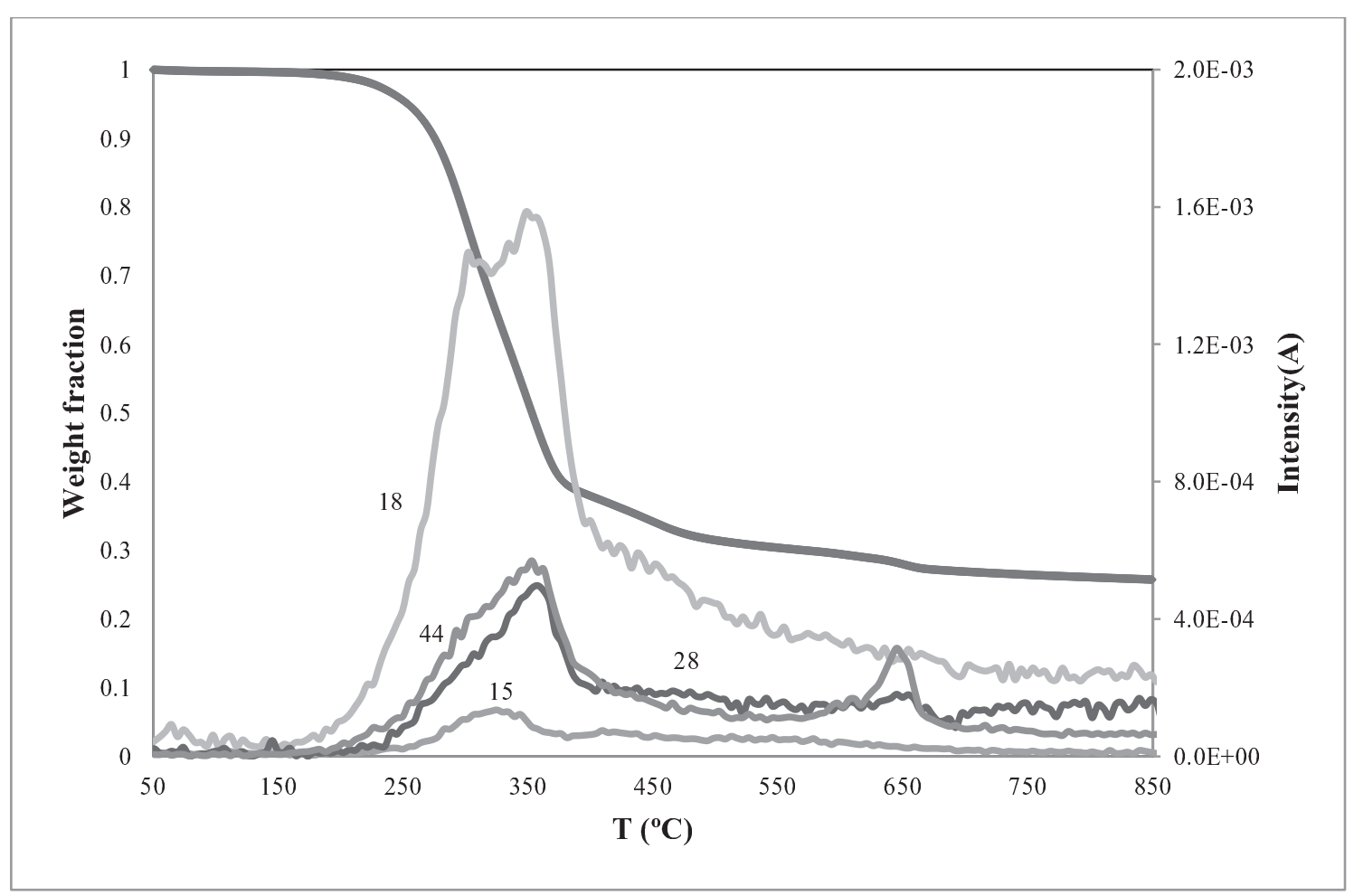

Figure 6. Intensities of some ions in a TG-MS run for wood waste pyrolysis. Ions: $15\left(\mathrm{CH}_{4}\right), 18$

$$
\left(\mathrm{H}_{2} \mathrm{O}\right), 28(\mathrm{CO}) \text { and } 44\left(\mathrm{CO}_{2}\right) \text {. }
$$




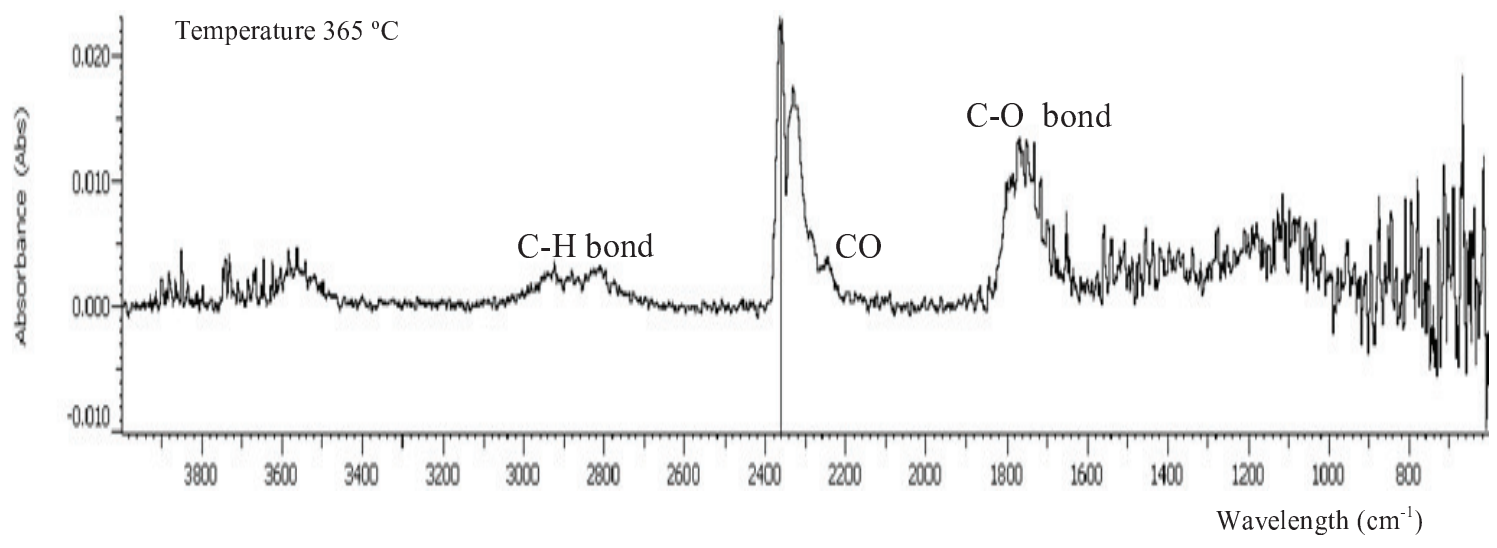

Figure 7. FTIR spectra of gas products from wood waste pyrolysis at $365^{\circ} \mathrm{C}$.

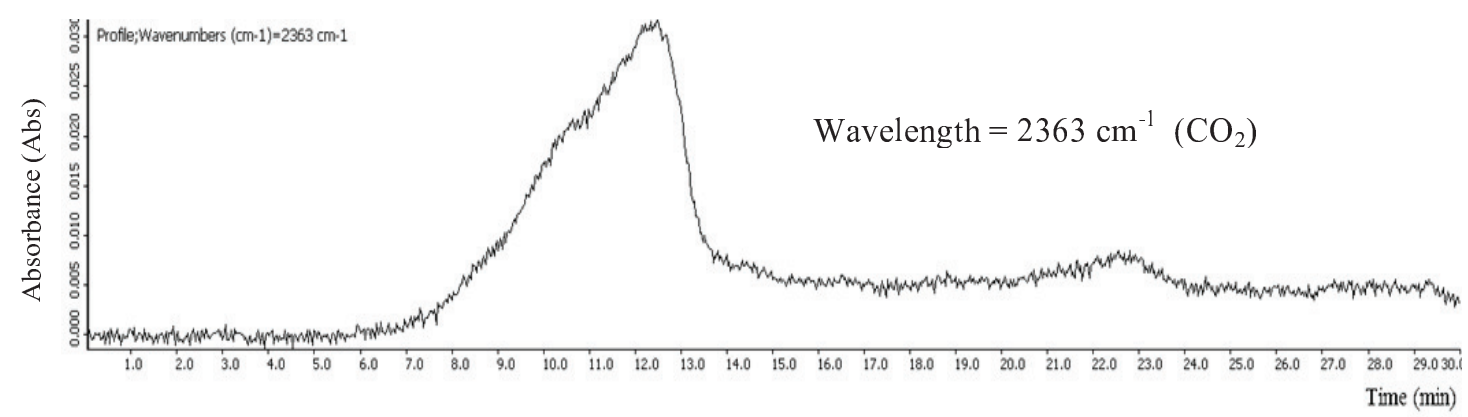

Figure 8. Evolution of formation of $\mathrm{CO}_{2}$ during wood waste pyrolysis.

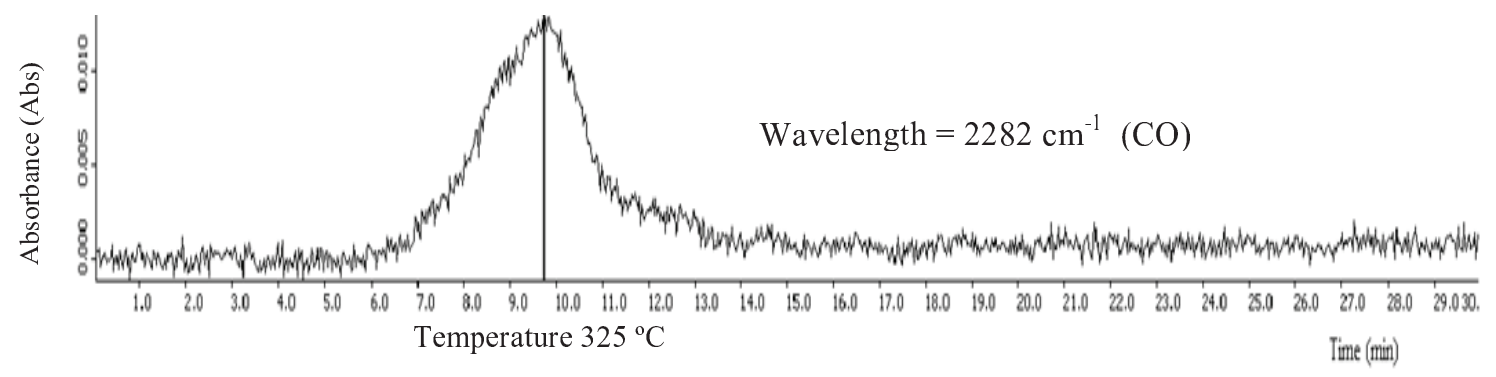

Figure 9. Evolution of formation of $\mathrm{CO}$ during wood waste pyrolysis. 